\title{
How the suicides In Japan decreased; comparison between urban and rural areas.
}

Nobuaki Eto, Leo Gotoh, Kenta Wada, Kohei Harada, Matsuo Mayuko, Hiroaki Kawasaki

Nobuaki Eto E-mail: etonobu@me.com

\section{Background}

Japan has had high suicide rates since 1998.

The suicide rate of total population sustained at about 25 $(/ 100,000)$ up to 2009 . [male $35-40$, female 13-15]

After 2009, it decreased gradually and resulted in $\mathbf{1 5 . 8}$ in 2016. [male 24.0, female 10.0]

\section{Suicide rate [Japanese National Police Agency]} $(/ 100,000)$

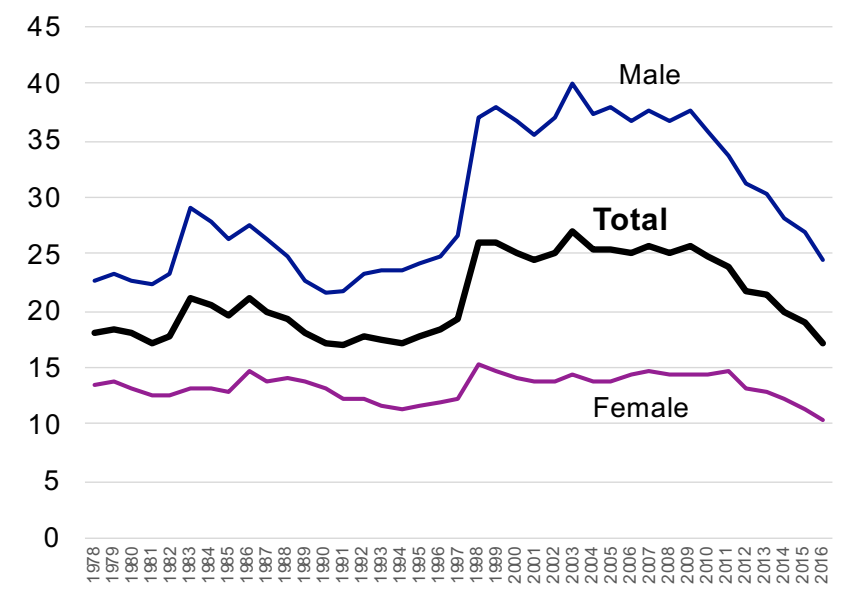

\section{Objective}

We analyzed the national data to investigate how the suicides in Japan decreased.

\section{Method}

We used the statistical data from Japanese National Police Agency.

This data is published annually, and it contains the number of suicides and suicide rate in each prefecture.

We divided 47 prefectures into two groups, urban areas and rural areas.

Urban area is defined as the area which has at least one government-ordinance-designated city (id. population is more than 700,000 ) in the prefecture.

We analyzed the annual data from 2006 to 2017. We compared the suicide rate of urban areas between those of rural areas.

\section{Results}

\section{4-1) Ratio of suicide rate in each year to 2011 urban vs rural areas}

- Suicide rates in rural areas had started to decrease from 2006.

- Whilst suicide rates in urban areas remained at the same level up to 2011 , then started to decrease more rapidly than rural areas after 2011.

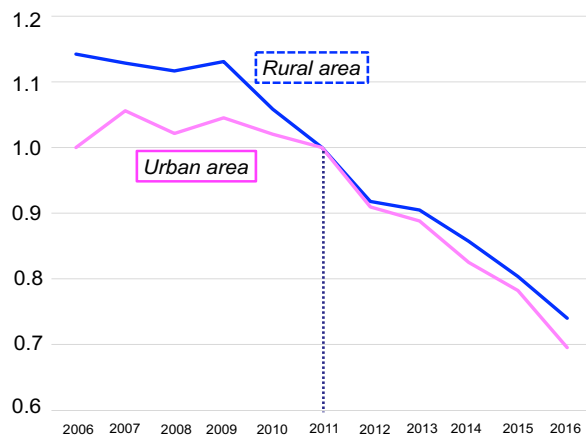

\section{4-2) Cluster Analysis}

Three prefectures (Miyagi, Hiroshima, Kumamoto) differed from other urban areas.

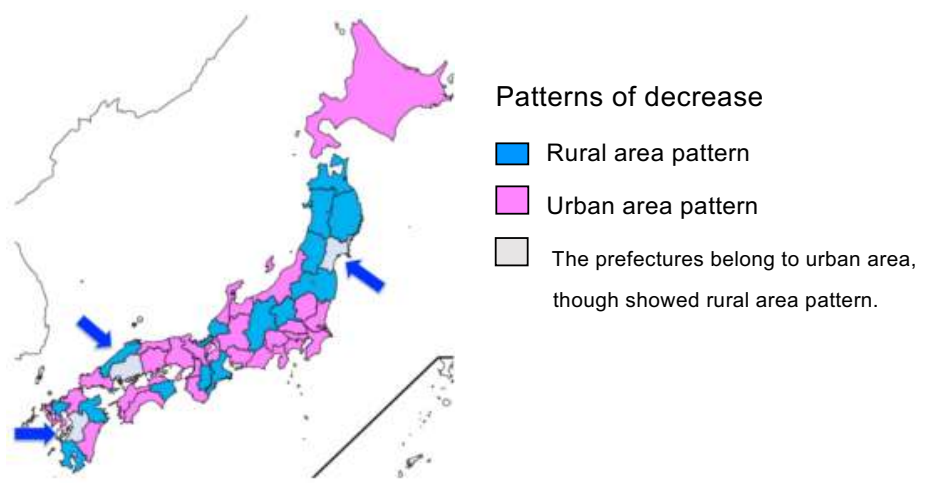

\section{Discussions}

- Cabinet of Japan established Basic Act on Suicide Prevention in 2006, and the Suicide Comprehensive Measures Outline in 2007. The effects of those policies and funds for suicide prevention (about 200 million dollars [2009 to 2014]) may show differently between urban areas and rural areas in the country.

- We thought urban areas may need more time to decrease suicides than rural area under the effect of suicide prevention activities.

- In the three urban prefectures showed different patterns, there were great natural disasters in this period. (Miyagi: earthquake in 2011, Hiroshima: heavy flood in 2014, Kumamoto: earthquake in 2016) Those may effect the results.

\section{Conclusion}

There were differences in the decreasing patterns between urban areas and rural areas. 